\title{
Synergistic Effect of Polyherbal Formulations on DPPH Radical Scavenging Activity
}

\author{
Nur Fazira Abdul Rahim, Norhayati Muhammad*, Norazlin Abdullah, Balkis A. Talip and \\ Nur Jihan Shahirah Dusuki
}

\begin{abstract}
Department of Technology and Natural Resources, Faculty of Applied Sciences and Technology,
Universiti Tun Hussein Onn Malaysia, Pagoh Educational Hub, 84600 Pagoh, Muar, Johor, Malaysia.
\end{abstract}

Received 30 September 2017; accepted 12 May 2018; available online 1 August 2018

DOI: https://10.30880/jst.2018.10.02.019

\begin{abstract}
Plant extracts contains huge number of chemical compounds that may give interaction effect which could affect the antioxidant properties especially when mixed together. Therefore, in this present study, the synergistic effect towards 2,2-diphenyl-1-picrylhydrazyl (DPPH) radical scavenging activity presence in aqueous extract of herbal leaves of Strobilanthes crispus (Pecah beling), Phyllanthus niruri (Dukung anak), Orthosiphon aristatus (Misai kucing) and Stevia rebudiana has been evaluated. Synergy is the interaction of two or more extracts to produce a combined effect greater than the totality of their individual effects. There were 22 formulations consisting various proportions of the extracts designated using the commercial statistical software package which is Design Expert 6.0.4. The in-vitro antioxidant study of the extracts and their different combinations were conducted by DPPH radical scavenging activity. The results suggest that $O$. aristatus has higher potential of antioxidant properties. Synergistic effect was exhibited in the majority of all combinations as well as the combination of the four plant extracts. The highest synergistic effect indicated in the fifth formulation ( $S$. crispus and $P$. niruri). However, the sixth formulation (S. crispus and S. rebudiana) showed the lowest synergistic effect. In conclusion, the present study justifies these polyherbal formulations have promising antioxidant properties in term of DPPH radical scavenging activity and validates their synergistic effect by having an improved activity in most of the formulations. Thus, it is sensible to mix the studied polyherbal formulations as food supplements or food ingredients in the future.
\end{abstract}

Keyword: Synergistic; DPPH; antioxidant; polyherbal formulations.

\section{Introduction}

High margin of safety, cost effective, ecofriendly and readily availability, had caused increasing development of herbal supplement involving traditional medicinal plants [1]. The medicinal plants are expected to have benefits such as a radical scavenging activity inhibitor, known as antioxidant. In nutraceutical and pharmaceutical industries, antioxidant plays a significant function as a health protecting factor which may reduce the risk of oxidative stressrelated diseases and able to give healthenhancing effect on human [2].

The ability to trap free radicals is the main role of an antioxidant which referred to as the oxygen-centered molecules that contain a single electron at the outermost orbit. In an extensive of sources, highly reactive free radicals and oxygen species are found in biological systems [3]. Thus, the study of biological activity and chemical composition of medicinal plant extracts as a potential source of natural antioxidants are becoming a trend in development of product.

S. crispus (pecah beling) from the Acanthaceae family is a well-known herb in Malaysia that has been reported to have various properties including antioxidant, antidiabetic, diuretic and wound healing activities as well as a hypolipidemic effect [4]. Meanwhile, $P$. niruri (dukung anak) is one of the herbal plants from the Euphorbiaceae family and the plant extract was widely used in the preparation of several Aayurvedic formulations [5]. Another herb, $O$. aristatus is a synonym to $O$. stamineus and locally known as "misai kucing" is belonging to the family Lamiaceae. It is found that the leaves display dynamic pharmacological properties such as strong antioxidant potency, antiurolithiatic, and total phenolic content [6]. The use of S. rebudiana belonging to the family Compositae in various formulations was mainly to improve the palatability of the formulation in which it acts as natural sweetener [7]. Nevertheless, the 
characteristic of good antioxidant with radical scavenging activity is its ability to put out the DPPH radical in the extracts [8].

Basically, plant extracts are natural component that might employ synergistic, antagonistic, additive and indifferent effect depending on the interaction on the phytochemicals [9]. In addition, combining of the plant extracts can also produce all those effects. To date, scientists are still exploring the possibilities of combining effect of the plant [10]. Synergistic effect is defined as a positive interaction when a combination of two or more substances shows higher mechanism than the sum of the single substances [11]. In other word, it is a new concept in development of food product from natural sources which can give optimum antioxidant effect due to harmful effects of synthetic antioxidants on human health [12].

Therefore, this study aims to investigate the synergistic effect of leaves extract of $S$. crispus, $P$. niruri, $O$. aristatus and $S$. rebudiana for polyherbal formulation followed by evaluation of their interaction effect towards DPPH radical scavenging activity.

\section{Materials and Methods}

Chemicals and instruments. DPPH (2,2diphenyl-1-picrylhydrazyl) was purchased from Merck Germany. The reagent of methanol was analytical grade procured from local sources. The instrument used was UV-Vis spectrophotometer (T60u, PG Instrument, USA) located in Food Analysis Laboratory, Universiti Tun Hussein Onn Malaysia.

Collection and Preparation of Plant Materials. Four types of plant materials which are $S$. crispus, $P$. niruri, $O$. aristatus and $S$. rebudiana were used in polyherbal formulations. They were purchased from local company of Ethno Resources in dried form. Referring to Muryanto, the preparation of leaves extracts was done with slight modifications [13]. The dried leaves of selected medicinal plants were grinded into powdered form using a standard laboratory blender. Next, $100 \mathrm{~g}$ of each plant powder was boiled slowly in $1000 \mathrm{~mL}$ of distilled water using low heat until the volume of the mixture reduced to about a third of the original volume. It was immersed in the hot water at range of $80^{\circ} \mathrm{C}$ to $90^{\circ} \mathrm{C}$ for 15 minutes. The extracts were filtered separately using sterile Whatman no 1 filter paper to get the supernatant mixture from the extraction solution while the residues were stored in cool condition for further use. For the polyherbal formulations development, the plant extracts were mixed in various proportions of 22 formulations as shown in Table 1, which has been designated using commercial statistical software package that is Design Expert 6.0.4.

Table 1 Design layout and experimental results

\begin{tabular}{|c|c|c|c|c|}
\hline \multirow{2}{*}{ 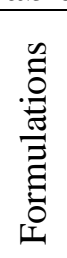 } & $\begin{array}{c}\text { Factor } 1 \\
(\%)\end{array}$ & $\begin{array}{l}\text { Factor } \\
2(\%)\end{array}$ & $\begin{array}{l}\text { Factor } \\
3(\%)\end{array}$ & $\begin{array}{c}\text { Factor } \\
4(\%)\end{array}$ \\
\hline & $\begin{array}{c}S . \\
\text { crispus }\end{array}$ & $\begin{array}{c}P . \\
\text { niruri }\end{array}$ & $\begin{array}{c}O . \\
\text { arista- } \\
\text { tus }\end{array}$ & $\begin{array}{c}S . \\
\text { rebu- } \\
\text { diana }\end{array}$ \\
\hline 1 & 0 & 0 & 0 & 100 \\
\hline 2 & 100 & 0 & 0 & 0 \\
\hline 3 & 33.33 & 33.33 & 33.33 & 0 \\
\hline 4 & 0 & 33.33 & 33.33 & 33.33 \\
\hline 5 & 50 & 50 & 0 & 0 \\
\hline 6 & 50 & 0 & 0 & 50 \\
\hline 7 & 62.5 & 12.5 & 12.5 & 12.5 \\
\hline 8 & 12.5 & 12.5 & 62.5 & 12.5 \\
\hline 9 & 12.5 & 12.5 & 12.5 & 62.5 \\
\hline 10 & 0 & 0 & 0 & 100 \\
\hline 11 & 0 & 100 & 0 & 0 \\
\hline 12 & 0 & 0 & 100 & 0 \\
\hline 13 & 100 & 0 & 0 & 0 \\
\hline 14 & 0 & 0 & 100 & 0 \\
\hline 15 & 0 & 50 & 0 & 50 \\
\hline 16 & 50 & 0 & 50 & 0 \\
\hline 17 & 0 & 0 & 50 & 50 \\
\hline 18 & 33.33 & 33.33 & 0 & 33.33 \\
\hline 19 & 33.33 & 0 & 33.33 & 33.33 \\
\hline 20 & 12.5 & 62.5 & 12.5 & 12.5 \\
\hline 21 & 0 & 50 & 50 & 0 \\
\hline 22 & 25 & 25 & 25 & 25 \\
\hline
\end{tabular}

DPPH Radical Scavenging Activity. Radical scavenging activity of polyherbal formulations against stable DPPH was determined spectrophotometrically. The reaction was showed when changes in colour (from deep violet to light yellow) are occurred. DPPH was reacted with an antioxidant compound, which can donate hydrogen and it was reduced. The absorbance of the mixture was measured at $517 \mathrm{~nm}$ on a UV-Vis spectrophotometer. The radical scavenging activity of each extract and polyherbal combination were measured according to previous method with slight modification [14, 
15]. The DPPH solution $(5.9 \mathrm{mg}$ in $100 \mathrm{~mL}$ methanol) was prepared daily before UV measurement. Three (3) mL of DPPH solution was mixed with $77 \mu \mathrm{L}$ of sample in cuvettes. The mixed samples are left at room temperature and in the dim area for 15 minutes. Then, the reduction in absorption reading was taken. For the blank sample, the same quantity of methanol and DPPH was prepared and the change in absorption was measured. All of the samples tested were required to be done in triplicate. The radical scavenging activity was calculated by the following formula:

$$
\% \text { Inhibition }=[(\mathrm{AB}-\mathrm{AA}) / \mathrm{AB}] \times 100
$$

Where: $\mathrm{AB}$ is absorption of blank sample ( $\mathrm{t}=0$ min) and $\mathrm{AA}$ is the absorption of tested extract solution $(\mathrm{t}=15 \mathrm{~min})$.

Calculation of Synergistic Effects on DPPH Radical Scavenging Activity. The experimental antioxidant capacity of the mixtures was calculated for each antioxidant assay. The percentage inhibition of each individual plant extract at each combination was used to calculate the predicted inhibition of the mixture. The calculated values were taken as the sum percentage inhibition of the individual percentage of inhibition in each mixture. Thus, the predicted inhibitions were used to compare with experimental percentage to determine the interaction effects [16]. If the experimental antioxidant activity was greater than the theoretical antioxidant activity, it was considered as synergistic effect and if it was lower than the theoretical antioxidant activity it was interpreted as antagonistic effect [17]. However, when the result show neither good nor bad after two or more mixtures was mixed, it was indicated as indifferent.

Statistical Analysis. The results were expressed as means \pm SD to show variations in the various experimental. Differences are considered significant when $p<0.05$ [18]. Oneway ANOVA was performed on mean data obtained on percentage inhibition on DPPH radical scavenging activity using commercial statistical software IBM SPSS Statistics 20 of Tukey- LSD.

\section{Results and Discussion}

In general, DPPH radical scavenging assay is widely used to evaluate the antioxidant properties of extracts from different plant materials [19].

Antioxidants have been initiated in many types of plant materials and supplements including S. crispus, P. niruri, O. aristatus and $S$. rebudiana. Due to their natural origin of the extracts, the use of natural antioxidant from plants does not induce side effect [19].

$O$. aristatus showed the highest antioxidant values of $78.84 \%$, followed by $P$. niruri $(72.90 \%)$, S. rebudiana $(64.69 \%)$ and the lowest was $S$. crispus with only $50.85 \%$ (Fig 1). The higher antioxidant properties in $O$. aristatus might be due to the properties of the plant that conferred with high amount of flavones, polyphenols, glycosides, bioactive active proteins, a volatile oil, and massive quantities of potassium [20]. Previous study of $O$. aristatus, indicated that total phenolic contents of the plant ranged from 139.81 to 386 gallic acid equivalents per gram of extract [21]. The content of phenolic and flavonoid compounds strongly link with the antioxidant activities of plant materials [22]. Therefore, $O$. aristatus has higher properties of antioxidant individually compared to other plant extracts. This might be because of total phenolic content in the plant is in compatible range compared to other extracts.

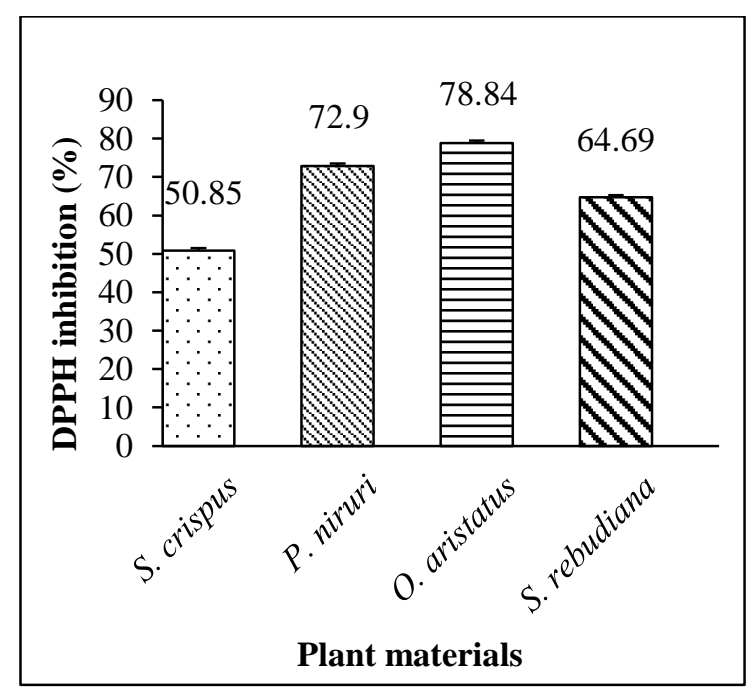

Fig. 1 DPPH Radical Scavenging Inhibition of Plant Extracts Individually 
However, when the plant extracts were combining with the other two or more plant extracts, some of them showed a significantly increased in DPPH radical scavenging abilities which indicates a synergistic effects (Table 2).

Table 2 Antioxidant values of mixtures containing two, three and four plant extracts

\begin{tabular}{|c|c|c|c|}
\hline \multirow{2}{*}{ 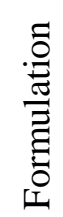 } & \multicolumn{2}{|c|}{ DPPH (\% inhibition) } & \multirow{2}{*}{$\begin{array}{c}\text { Type of } \\
\text { interaction }\end{array}$} \\
\hline & $\begin{array}{l}\text { Predic- } \\
\text { ted } \\
\text { values }\end{array}$ & $\begin{array}{l}\text { Experimental } \\
\text { values }\end{array}$ & \\
\hline 3 & 67.53 & $86.78 \pm 3.53^{\mathrm{ab}}$ & Synergistic \\
\hline 4 & 72.14 & $86.72 \pm 0.85^{\mathrm{ab}}$ & Synergistic \\
\hline 5 & 61.88 & $88.65 \pm 7.70^{\mathrm{a}}$ & Synergistic \\
\hline 6 & 57.78 & $57.86 \pm 1.29^{\mathrm{efg}}$ & Indifferent \\
\hline 7 & 58.84 & $69.84 \pm 2.13^{\text {cde }}$ & Synergistic \\
\hline 8 & 72.84 & $77.15 \pm 3.26^{\mathrm{abcd}}$ & Synergistic \\
\hline 9 & 65.76 & $67.96 \pm 1.98^{\text {cde }}$ & Synergistic \\
\hline 15 & 68.80 & $91.23 \pm 0.18^{\mathrm{a}}$ & Synergistic \\
\hline 16 & 64.85 & $90.13 \pm 0.82^{a}$ & Synergistic \\
\hline 17 & 71.77 & $67.31 \pm 2.14^{\text {cdef }}$ & Antagonistic \\
\hline 18 & 62.81 & $66.39 \pm 4.09^{\text {def }}$ & Synergistic \\
\hline 19 & 64.79 & $70.64 \pm 4.24^{\text {cde }}$ & Synergistic \\
\hline 20 & 69.87 & $69.24 \pm 15.85^{\text {cde }}$ & Indifferent \\
\hline 21 & 75.87 & $65.47 \pm 3.72^{\text {def }}$ & Synergistic \\
\hline 22 & 66.82 & $65.47 \pm 3.72^{\mathrm{def}}$ & Indifferent \\
\hline
\end{tabular}

Different letter at each line indicates significant differences $(p<0.05)$

Only one of the polyherbal formulations showed the antagonistic interactions $\left(17^{\text {th }}\right.$ formulation). The highest synergistic effect showed in the fifth formulations which $S$. crispus was combined with $P$. niruri while a lowest synergistic effect showed in the $21^{\text {st }}$ formulation which was the combination of $S$. crispus and $S$. rebudiana. This might be because $S$. cripus has terpene compounds which reported to have synergistic effect in antioxidations with other antioxidants [23]. Besides that, the presence of bioactive compounds in $P$. niruri extracts helps in contributing synergistic effects as it was stated to have antioxidant capabilities in the free radical scavenging activity [24]. Therefore, it is applicable to mix the plant extracts in the formulations to have a good product development with optimum antioxidant properties [25].

\section{Conclusion}

It can be concluded that most of the polyherbal formulations of the aqueous extracts in this study showed the synergistic interaction towards DPPH radical scavenging activity. Thus, this finding may leads to the understandable product development in the future particularly in the studied herbs.

\section{Acknowledgements}

This research was supported by Universiti Tun Hussein Onn Malaysia and Fundamental Research Grant Scheme (FRGS), Vot number 1646.

\section{References}

[1] Jain, S.K., (2006). "Notable Foreign Medicinal Uses for Some Plants of Indian Tradition" in Indian Journal Traditional Knowledge, Vol. 2. pp. 321-332.

[2] Adorjan, B. \& Buchbauer, G. (2010). "Biological Properties of Essential Oils: An Updated Review" in Flavour and Fragrance Journal, Vol. 25. No. 6 pp. 407426.

[3] Lobo, V., Patil, A., Phatak, A., \& Chandra, N. (2010). "Free Radicals, Antioxidants and Functional Foods: Impact on Human Health" in Pharmacognosy Reviews, Vol. 4. No. 8 pp. 118.

[4] Qader, S.W., Abdulla, M.A., Chua, L.S., Najim, N., Zain, M. M., \& Hamdan, S. (2011). "Antioxidant, Total Phenolic Content and Cytotoxicity Evaluation of Selected Malaysia Plants" in Moleculte, Vol. 16. No. 4 pp. 3433-3443.

[5] Barror, M., Schor, A. \& Boim, M. (2003). "Effects of an Aqueous Extract from Phyllanthus Niruri on Calcium Oxalate Crystallization In Vitro" in Urology Research, Vol. 30 No. 6 pp. 374-379.

[6] Akowuah, G.A, Zhari, I., Norhayati, I., Sadikun, A., \& Khamsah, S.M. (2004). "Sinensetin, Eupatorin, 3' Hydroxy-5, 6, 7, 4'Tetramethoxyflavone and Rosmarinic Acid Contents and Antioxidative Effect of Orthosiphon Stamineus from Malaysia" in Food Chemistry, Vol. 87. pp. 559-566.

[7] Goyal, S., Samsher \& Goyal, R. (2010). "Stevia (Stevia Rebudiana) a Biosweetener: a Review" in International 
Journal Food Science and Nutrition, Vol. 61. pp. 1-10.

[8] Ruiz-Ruiz, J.C., Moguel-Ordoñez, Y.B., Matus-Basto, A.J., \& Segura Campos, M. R. (2015). "Antidiabetic and Antioxidant Activity of Stevia Rebudiana Extracts (Var. Morita) and Their Incorporation into Potential Functional Bread" in Journal of Food Science and Technology, Vol. 52. No. 12 pp. 7894- 7903.

[9] Wang, S., Meckling, K.A., Marcone, M.F., Kakuda, Y., \& Tsao, R. (2011). "Synergistic, Additive, and Antagonistic Effect of Food Mixture on Total Antioxidant Capacities" in Journal of Agricultural and Food Chemistry, Vol. 59. No. 3 pp. $960-968$.

[10] Brigitte, L., Emmanuel, T., Kouam, J., Zra, T., Louis, O.E.J. (2013). "Synergetic Effects of Plant Extracts and Antibiotics on Vibrio Cholera O1 Strains Isolated from Clinical Specimens" in International Journal of Biology, Vol. 5 No. 3 pp. 64-72.

[11]Blesson, J., Saji, C.V., Nivya R.M., Kumar, R. (2015). "Synergistic Antibacterial Activity of Natural Plant Extracts and Antibiotics against Methicilin Resistant Staphylococcus Aureus (Mrsa), Vol. 4. No. 3 pp. 741-763.

[12] Sheng, Z.W., Ma, W.H., Gao, J.H., Bi, Y., Zhang, W.M., Duo, H.T. and Jin, Z.Q. (2011). "Antioxidant Properties of Banana Flower of Two Cultivars in China Using 2, 2-diphenyl-1-picrylhydrazyl (DPPH) Reducing Power, 2, 2'- azinobis(3ethylbenzthiazoline-6-sulphonate)

(ABTS) and Inhibition of Lipid Peroxidation Assays" in African Journal of Biotechnology, Vol. 10. No. 21 pp. 44704477.

[13] Muryanto, S., Hadi, S.D., Purwaningtyas, E.F., \& Bayuseno, A.P. (2014). "Effect of Orthosiphon Aristatus Leaves Extract on the Crystallization Behavior of Struvite". Department of Chemical Engineering, University, Tembalang Campus, Semarang, Indonesia.

[14] Bondet, V., Williams, B. W., \& Berset, C. (1997). "Kinectic and Mechanisms of Antioxidant Activity Using the DPPH Free Radical Method" in Lebensm. Wiss. Urology Technology, Vol. 3. pp. 609-615.

[15] Miliauskas, G., Venskutonis, P., \& Van Beek, T. (2004). "Screening of Radical Scavenging Activity of Some Medicainal and Aromatic Plant Extracts" in Food Chemistry, pp. 231-237.

[16] Hugo, P.C., Joana, G.G., Rogerio R.S.M., Namiesnik, J., Gorinstein, S. \& Gustavo A.G.A. (2012). "Antioxidant Interactions between Major Phenolic Compounds Found in "Ataulfo" Mango Pulp: Chlorogenic, Gallic, Protocatechuic and Vanillic Acids" in Molecules, Vol. 17. No. 11 pp. 12657-12664.

[17]Liu, D., Shi, J., Ibarra, A. C., Kakuda, Y., \& Xue, S. J. (2008). "The Scavenging Capacity and Synergistic Effects of Lycopene, Vitamin E, Vitamin C, And BCarotene Mixtures on the DPPH Free Radical" in Food Science and Technology, Vol. 2008. No. 41 pp. 1344-1349.

[18] Ao, T., Pierce, J. L., Power, R., Pescatore, A. J., Cantor, A. H., Dawson, K. A., \& Ford, M. J. (2009). "Effects of Feeding Different Forms of Zinc and Copper on the Performance and Tissue Mineral Content of Chicks" in Poultry Science, Vol. 88. No. 10 pp. 2171-2175.

[19] Stanković, M.S., (2011). “Total Phenolic Content, Flavonoid Concentration and Antioxidant Activity of Marrubium Peregrinum L. Extracts" in Kragujevac Journal of Science, Vol. 33. pp. 63-72.

[20]Chai, T., Wong, F.C., Abd Manan, F., Ooh, K.F., \& Ni, M. (2014). "Orthosiphon Aristatus: A Review of Traditional Uses, Phytochemical Profile, and Pharmacological Properties. Traditional and Folk Herbal Medicine in Recent Researches, pp. 153-187.

[21] Abdelwahab, S.I., Mohan, S., Mohamed Elhassan, M., Al-Mekhlafi, N, Mariod, A.A., Abdul, A.B., Abdulla, M.A., and Alkharfy, K.M. (2011). "Antiapoptotic and AntioxidantProperties of Orthosiphon Stamineus Benth (Cat's Whiskers): Intervention in the Bcl-2-Mediated Apoptotic Pathway" in Evidence based Complementary and Alternative Medicine.

[22] Velioglu Y.S., Mazza G., Gao L., Oomah B.D. (1998). "Antioxidant Activity and Total Phenolics in Selected Fruits, Vegetables, and Grain Products" in Journal Agricultural of Food Chemistry, Vol. 46. No. 10 pp. 4113-4117.

[23] Rahmat, A., Edrini, S., Ismail, P. Hin, T.Y.Y. \& Bakar, M.A. (2006). "Chemical Constituents, Antioxidant Activity and Cytotoxic Effects of Essential Oil from 
Strobilanthes Crispus and Lawsonia Inermis," Journal of Biological Sciences, Vol. 6. No. 6 pp. 1005-1010.

[24] Yu, J., Wang, L., Walzem, R.L., Miller, E.G., Pike, L.M., \& Patil, B. S. (2005). "Antioxidant Activity of Citrus Limonoids, Flavonoids, and Coumarins," Journal of Agricultural and Food Chemistry, Vol. 53. No. 6 pp. 2009-2014.

[25] Amarowicz, R, Pegg, R.B, Rahimi Moghaddam, P., Barl, B. \& Weil, J.A. (2004). "Free Radical-Scavenging Capacity and Antioxidant Activity of Selected Plant Species from the Canadian prairie" in Food Chemistry, Vol. 84. pp. 551-562. 